Check for updates

Cite this: RSC Adv., 2019, 9, 23444

\title{
Neodymium $\beta$-diketonate showing slow magnetic relaxation and acting as a ratiometric thermometer based on near-infrared emission $\uparrow$
}

\author{
Kunal Kumar, (DD a Daisuke Abe, ${ }^{a}$ Keiko Komori-Orisaku, (D) a Olaf Stefańczyk, (DD ${ }^{a}$ \\ Koji Nakabayashi, ${ }^{a}$ Julia R. Shakirova, ${ }^{b}$ Sergey P. Tunik (D) $^{\mathrm{b}}$ and Shin-ichi Ohkoshi (D) *a
}

\begin{abstract}
Self-assembly of $\beta$-diketonate ( $\mathrm{Htta}=$ thenoyl(trifluoro)acetone) and 4,4'-azopyridine (Azo-py) with neodymium(III) ions in the presence of methanol resulted in the formation of mononuclear complex $\left[\mathrm{Nd}^{\prime \prime \prime}(\mathrm{TTA})_{3}(\mathrm{MeOH})_{2}\right] \cdot 0.5 \mathrm{AzO}-$ py (A) in which two asymmetric units are linked by Azo-py through hydrogen bonding via methanol. A reveals near-infrared emission (NIR) centred at about 895 and $1056 \mathrm{~nm}$, in the 10-370 $\mathrm{K}$ temperature range, originating from the two emissive transitions on $\mathrm{Nd}\left({ }_{11}\right)$ from ${ }^{4} \mathrm{~F}_{3 / 2}$ to ${ }^{4} \mathrm{I}_{9 / 2}$ and ${ }^{4} \mathrm{I}_{11 / 2}$ levels, respectively. Furthermore, the NIR luminescence intensity of $A$ at room temperature augments two times upon thermal elimination of one coordinated methanol molecule. The thermally activated $\mathrm{A}$ exhibits single centre ratiometric thermometer behaviour in a wide temperature range from 10 to $300 \mathrm{~K}$. Moreover, fluorescence properties of $\mathrm{A}$ were compared to another mononuclear complex $\left[\mathrm{Nd}^{\prime \prime \prime}(\mathrm{TTA})_{3}(4-\mathrm{OHpy})\left(\mathrm{H}_{2} \mathrm{O}\right)\right]$ (B). Assembly $\mathrm{A}$ also exhibits field-induced slow magnetic relaxation properties with an energy barrier of $\Delta E / k_{\mathrm{B}}=19.7(7) \mathrm{K}$ and an attempt time of relaxation, $\tau_{0}=3.7(8) \times 10^{-7} \mathrm{~s}$ for fresh sample $\mathrm{A}$, and $\Delta E / \mathrm{k}_{\mathrm{B}}=27.3 \mathrm{~K}$ and $\tau_{0}=8.5(0) \times 10^{-8}$ for assembly $A$ after thermal treatment at $370 \mathrm{~K}$.
\end{abstract}

Received 2nd May 2019

Accepted 14th July 2019

DOI: $10.1039 / c 9 r a 03276 b$

rsc.li/rsc-advances

\section{Introduction}

In recent years, much attention has been devoted to the synthesis and characterization of molecule-based materials with linkers (cyanide and thiocyanide) or chelating ligands ( $\beta$ diketonates) showing various properties such as magnetism ${ }^{1}$ and luminescence. ${ }^{2}$ Especially, multifunctional materials with two or more physical properties have been broadly investigated which includes photo-magnetic, ${ }^{3}$ magneto-luminescent ${ }^{4}$ and humidity sensitive materials. ${ }^{5}$ The $\beta$-diketonate hybrid complexes are one of the longest explored class of chelating ligands due to their ability to stabilize the crystal framework which has found practical application in the design of technological devices. ${ }^{6}$ Meanwhile, trivalent lanthanides complexes have an intrinsic nature to exhibit excellent visible $(\mathrm{VIS})^{7}$ and near-infrared (NIR) $)^{8}$ luminescence along with single molecule magnet (SMM) behavior due to sharp f-f electronic

\footnotetext{
${ }^{a}$ Department of Chemistry, School of Science, The University of Tokyo, 7-3-1 Hongo, Bunkyo-ku, Tokyo 113-o033, Japan. E-mail: ohkoshi@chem.s.u-tokyo.ac.jp

${ }^{b}$ Institute of Chemistry, St.-Petersburg State University, 26 Universitetskiy Pr., Petergof, St.-Petersburg, Russia

$\dagger$ Electronic supplementary information (ESI) available: Experimental details, IR and UV-Vis-NIR absorption spectra, TGA data, structural figures, structural parameters, PXRD patterns, additional emission and excitation spectra, ac magnetic plots, and parameters used for the fitting of Argand plots. CCDC 1900260-1900262. For ESI and crystallographic data in CIF or other electronic format see DOI: 10.1039/c9ra03276b
}

transitions and magnetic anisotropy. SMMs exhibiting magnetic hysteresis below a blocking temperature have potential in diverse research areas. ${ }^{9}$ Moreover, SMMs based on 4f-metal ions are promising candidates for luminescent magnets and have the flexibility to incorporate other functionalities. Thus, rare-Earth $\beta$-diketonates are suitable materials to be used in light-emitting diodes, spintronics and high density information storage. ${ }^{10}$ The potential hidden in molecule-based materials with lanthanide ions encourages us to look for molecular luminescent thermometers based on NIR emission. The working principle behind such thermometers is to utilize the temperature dependence of the luminescence, emission intensity, peak energy, integrated area of the peak, and lifetime or anisotropy. Recently, we have reported two molecular thermometers $\left\{\left[\mathrm{Tb}_{1-x} \mathrm{Dy}_{x}(4-\mathrm{OHpy})_{2}\left(\mathrm{H}_{2} \mathrm{O}\right)_{3}\right]\right.$ $\left.\left[\mathrm{Co}(\mathrm{CN})_{6}\right]\right\} \cdot 0.5 \mathrm{H}_{2} \mathrm{O}(x=0$ and 0.5$)$ based on cyanido-bridged metal assemblies showing colorometric as well as ratiometric thermometeric behaviour utilizing the intrinsic thermally reliant visible emission of $\mathrm{Tb}^{\mathrm{III}}$ and Dy ${ }^{\mathrm{III}}$ ions. ${ }^{11 a}$ In the pursuit to find multi-functional molecular thermometer, we synthesized neodymium $\beta$-diketonate complexes with molecular formula of $\left[\mathrm{Nd}^{\mathrm{III}}(\mathrm{TTA})_{3}(\mathrm{MeOH})_{2}\right] \cdot 0.5$ Azo-py (A), using organic ligand as a linkers, where TTA stands for trifluoro-1-(2thienyl)-1,3-butanedione and Azo-py is 4,4'-azopyridine. Furthermore, we compared $\mathbf{A}$ with another fluorescent compound: $\left[\mathrm{Nd}^{\mathrm{III}}(\mathrm{TTA})_{3}(4-\mathrm{OHpy})\left(\mathrm{H}_{2} \mathrm{O}\right)\right]$ (B) to elucidate the mechanism of fluorescence effect in $\mathbf{A}$. 


\section{Experimental}

\section{Materials}

Neodymium(III) chloride hexahydrate $\left(\mathrm{Nd}^{\mathrm{III}} \mathrm{Cl}_{3} \cdot 6 \mathrm{H}_{2} \mathrm{O}\right.$, CAS: 13477-89-9), 4,4,4-trifluoro-1-(2-thienyl)-1,3-butanedione (TTA, CAS: 326-91-0), 4-hydroxypyridine (4-OHpy, CAS: 626-64-2), 4,4'azopyridine (Azo-py, CAS: 2632-99-7) and sodium hydroxide (NaOH, CAS: 1310-73-2) were purchased from commercial sources (Sigma-Aldrich, Tokyo Chemical Industry Co., Ltd., and Wako Pure Chemical Industries, Ltd).

\section{Syntheses of $\left[\mathrm{Nd}^{\mathrm{III}}(\mathrm{TTA})_{3}(\mathrm{MeOH})_{2}\right] \cdot 0.5 \mathrm{Azo}-\mathrm{py}(\mathrm{A})$ and $\left[\mathrm{Nd}^{\text {III }} \text { (TTA) }\right)_{3}$ (4-OHpy)( $\left.\left.\mathrm{H}_{2} \mathrm{O}\right)\right]$ (B)}

Assemblies $\mathbf{A}$ and $\mathbf{B}$ were obtained from $5 \mathrm{~mL}$ methanol solution of $\mathrm{Nd}^{\mathrm{III}} \mathrm{Cl}_{3} \cdot 6 \mathrm{H}_{2} \mathrm{O}(0.6 \mathrm{mmol})$ and TTA $(1.8 \mathrm{mmol})$ treated with $\mathrm{NaOH}(1.8 \mathrm{mmol})$ upon vigorous stirring. After 10 minutes of mixing, the purple filtrate $\mathbf{X}$ was collected using vacuum filtration. Successive addition of $5 \mathrm{~mL}$ methanol solution of Azo-py or 4-OHрy ( $0.6 \mathrm{mmol})$ to solution $\mathbf{X}$ and then slow evaporation for 4 days results in formation block shaped crystals of $\mathbf{A}$ and $\mathbf{B}$, respectively. All products were collected by filtration, washed with small amount of methanol and used for further characterization. $\left[\mathrm{Nd}^{\mathrm{III}}(\mathrm{TTA})_{3}(\mathrm{MeOH})_{2}\right] \cdot 0.5$ Azo-py (A): yield: $414 \mathrm{mg}$ (68\%). Anal. calcd. for $\mathrm{NdC}_{31} \mathrm{H}_{24} \mathrm{~F}_{9} \mathrm{~N}_{2} \mathrm{O}_{8} \mathrm{~S}_{3},\left(M_{\mathrm{W}}=967 \mathrm{~g} \mathrm{~mol}^{-1}\right)$ : Nd, $14.9 \%$; C, 38.5\%; H, 2.8\%; N, 2.9\%; F, 17.7\%; S, 9.95\%. Found: Nd, $14.5 \%$; C, 38.4\%; H, 2.8\%; N, 2.9\%; F, $17.6 \% ; \mathrm{S}$, 10.0\%. $\left[\mathrm{Nd}^{\mathrm{III}}(\mathrm{TTA})_{3}(4-\mathrm{OHpy})\left(\mathrm{H}_{2} \mathrm{O}\right)\right](\mathbf{B})$ : yield: $380 \mathrm{mg}(40 \%)$. Anal. calcd. for $\mathrm{NdC}_{30} \mathrm{H}_{23} \mathrm{~F}_{9} \mathrm{~N}_{1} \mathrm{O}_{9} \mathrm{~S}_{3},\left(M_{\mathrm{W}}=952.9 \mathrm{~g} \mathrm{~mol}^{-1}\right)$ : $\mathrm{Nd}$, 15.3\%; C, 37.8\%; H, 2.4\%; N, 1.5\%; F, 17.9\%; S, 10.1\%. Found: Nd, 15.5\%; C, 37.5\%; H, 2.3\%; N, 1.5\%; F, 17.9\%; S, 10.3\%.

\section{X-ray crystallography}

Single-crystal diffraction measurements at $90 \mathrm{~K}$ for crystals of $\mathbf{A}$ and $\mathbf{B}$, immersed in a paratone $\mathrm{N}$-oil and mounted on Micro Mounts holder, were conducted using Rigaku R-axis RAPID diffractometer. Collected data were processed by using RAPID AUTO (Rigaku). Crystal structures were solved by a direct method with SIR2011 (ref. 12) for A and SHELXS97 (ref. 13) for B using CrystalStructure 4.2 crystallographic software package ${ }^{\mathbf{1 4}}$ with the exception of refinement, which was performed using SHELXL-2018/3 (ref. 15) by a full-matrix least-squares technique. For disordered parts, isotropic refinements were performed. The disordered model was fixed with some restraints and constraints. Molecular graphics were prepared using Mercury 3.8 software. $^{16}$

\section{Physical techniques}

Infrared absorption spectra were measured on a JASCO FTIR4100 spectrometer for the pellet prepared by grinding together polycrystalline samples and $\mathrm{KBr}$. UV-VIS-NIR diffuse reflectance spectra were performed by means of JASCO V-670 spectrophotometer for the powdered mixture of the crystalline sample and barium sulphate. The elemental analyses were performed by a standard microanalytical method. Thermogravimetric analysis of the polycrystalline samples were measured using Rigaku Thermo Plus TG8120 apparatus from 20 to $400{ }^{\circ} \mathrm{C}$ under an air atmosphere with a sweeping rate of $2{ }^{\circ} \mathrm{C}$ and with aluminium oxide as a reference. Emission and excitation spectra were measured on a Horiba Jobin-Yvon Fluorolog-3 (FL3-211) spectrofluorometer (model TKN-7) equipped with a Xe $(450 \mathrm{~W})$ lamp as an excitation source with the liquid nitrogen cooled InGaAs NIR linear array detectors working in a photon-counting mode. Temperature dependent NIR emission and excitation spectra were measured using the above spectrofluorometer and NIR detector where samples were mounted between two quartz glass inside the cryostat connected to a temperature controller. Temperature dependent UVVIS-NIR absorption spectra were measured using Shimadzu UV3600plus_MPC-603. Magnetic properties were measured using a Quantum Design MPMS XL magnetometer. The crystalline compounds were put with a paraffin oil to avoid the rotation of the sample under an applied magnetic field. The diamagnetic contributions from the sample, oil and the holder were estimated and corrected.

\section{Computational details}

DFT calculations were performed using the Gaussian 09 program package. ${ }^{17}$ The geometries of the models were not optimized and the coordinates from crystal structure are employed as the starting structure. Calculations were performed using the unrestricted Becke three-parameter hybrid functional with the Lee-Yang-Parr correlation functional (B3LYP $)^{18}$ with the 6-31G(d,p) basis set. TD-DFT calculations were performed using UB3LYP to calculate the first 100 doublet transitions. Continuous Shape Measure Analysis for coordination spheres of $\left[\mathrm{Nd}^{\mathrm{III}}(\mathrm{TTA})_{3}(\mathrm{MeOH})_{2}\right]$ was performed using SHAPE software ver. 2.1.19

\section{Results and discussion}

Red crystals of A were synthesized following previously reported method $^{20}$ under basic condition by mixing $\mathrm{NdCl}_{3} \cdot 6 \mathrm{H}_{2} \mathrm{O}$ with HTTA and Azo-py in methanol (ESI $\dagger$ ). Single-crystal X-ray diffraction analysis reveals that compounds $\mathbf{A}$ crystallize in the centrosymmetric monoclinic $P 2_{1} / c$ space group (Fig. 1, and S4-S6 and Tables S1-S3, ESI $\dagger$ ). Asymmetric unit consists of eight coordinated $\mathrm{Nd}^{\mathrm{III}}$ ion connected by three TTA and two methanol molecules along with half equivalent of noncoordinated Azo-py. The crystalline material depicts eightcoordinated distorted square antiprism geometry around the $\mathrm{Nd}$ (III) ions as revealed by the continuous shape measure analysis (Table S3, ESI $\dagger$ ). Similar geometry and ligands arrangement were observed for other $\mathrm{Ln}^{\mathrm{III}}$-TTA systems. ${ }^{21}$ All 2-thiophene rings are oriented oppositely to the methanol connected to Azopy in the pseudo " $f a c$ " geometry. Crystal packing of this complex is supported by hydrogen bonding between Azo-py and methanol (one methanol out of two in anisotropic unit), $\pi \cdots \pi$ interactions among 2-thiophene rings to another 2-thiophene and azo groups (Fig. S5, ESI $\dagger$ ). The crystallinity and purity of bulk sample were confirmed by temperature-dependent powder $\mathrm{X}$-ray diffraction measurements, infrared (IR) spectroscopy, 
(a)

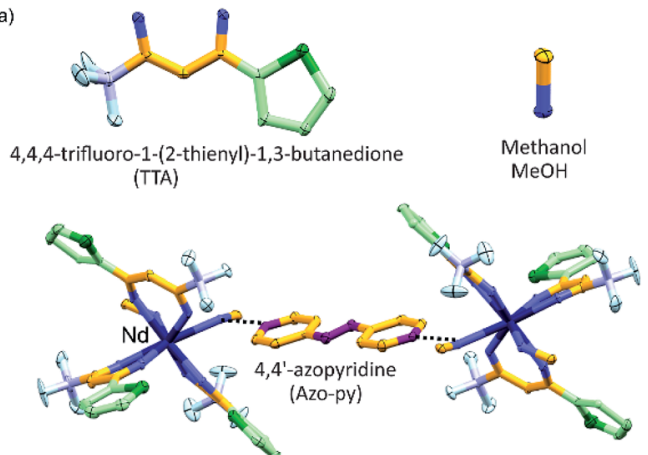

(b)

(c)
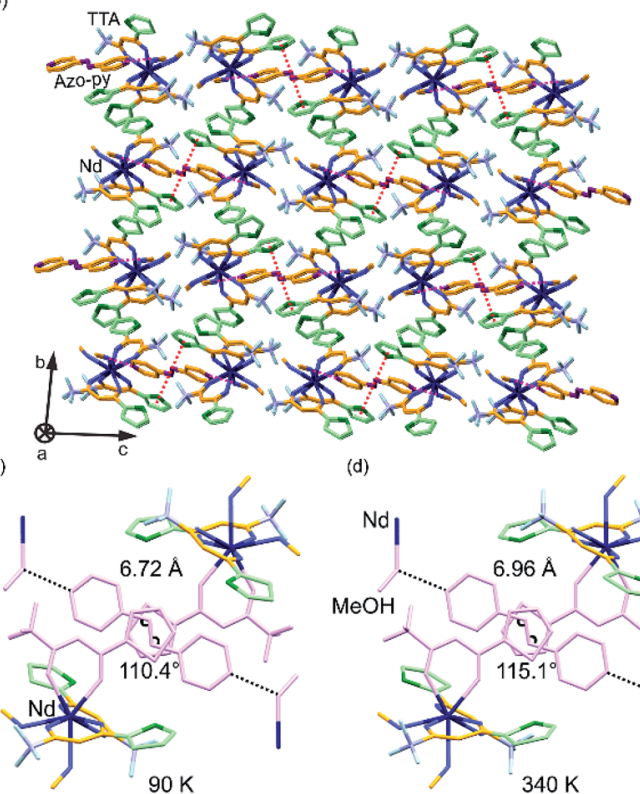

(d)

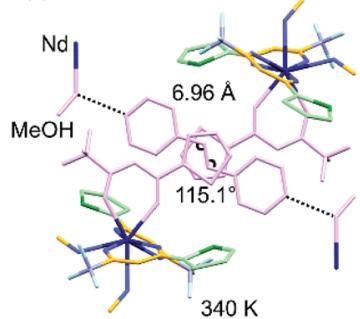

Fig. 1 The structural unit of $A$ with skeleton of $\beta$-diketonate ligand and methanol (a), the crystal packing along a crystallographic direction with partial overlap of Azo-py with 2-thiophene rings - red dotted lines and the hydrogen bonding between $\mathrm{MeOH}$ and $\mathrm{AzO}$-py - orange dotted lines (b), and the view along $b$-axis with comparison of the deformed $\mathrm{C}-\mathrm{N}-\mathrm{N}$ bond angle and distance between two centroids of 2-thiophene ring at $90 \mathrm{~K}$ (c) and $340 \mathrm{~K}$ (d). Black dotted line indicates hydrogen bonding.

thermogravimetric (TGA) and elemental analyses (Fig. S1-S3 and S7, ESI $\dagger$ ). The optical properties of A including UV-VIS-NIR absorption, emission and excitation spectra measured at different temperatures are shown in Fig. 2 and S8-S14 (ESI $\dagger$ ). The absorption spectra in the UV-VIS range have five characteristic peaks of Azo-py and TTA which are related to the combined contribution of singlet to singlet transitions $(\pi \rightarrow$ $\pi^{*}$ ) from the organic ligands (Fig. S8-S10 and Table S4, ESI $\dagger$ ). Additionally, sharp peaks in VIS-NIR region are assigned to the various $\mathrm{f}-\mathrm{f}$ transitions coming from $\mathrm{Nd}^{3+}$ ion. NIR emission spectra of A reveal two sharp peaks centred around 895 and $1056 \mathrm{~nm}$, originating from ${ }^{4} \mathrm{~F}_{3 / 2}$ to ${ }^{4} \mathrm{I}_{9 / 2}$ and ${ }^{4} \mathrm{I}_{11 / 2}$ transitions on neodymium(III), respectively (Fig. 2). ${ }^{22}$ The excitation spectra of A are centred around $360 \mathrm{~nm}$ with contribution exclusively from TTA and they also have sharp transitions of $\mathrm{Nd}^{3+}$ in the 450$650 \mathrm{~nm}$ range (Fig. 2b).
The very weak emission signal of $\mathbf{A}$ at room temperature might be caused by less efficient energy transfer from TTA to $\mathrm{Nd}(\mathrm{III})$. Consequently, we prepared reference compound $\left[\mathrm{Nd}^{\mathrm{III}}(\mathrm{TTA})_{3}(4-\mathrm{OHpy})\left(\mathrm{H}_{2} \mathrm{O}\right)\right](\mathrm{MeOH})(\mathbf{B})$ with coordinated 4-pyridinol (4-OHpy), (Fig. S1, S2, S6, S7 and S9 and Tables S1 and S2, ESI $\dagger$ ), to confirm the previous observation. As indicated in Fig. S11 (ESI $\dagger$ ) the emission and excitation spectra of $\mathbf{B}$ have relatively high intensity and the excitation spectra maxima compared to A are shifted to $392 \mathrm{~nm}$ which proves the role of coordinated 4-OHpy in transferring the energy efficiently to the $\mathrm{Nd}^{\mathrm{III}}$. Moreover, to unravel the coordination effect on the luminescence properties, A was heated from $10 \mathrm{~K}$ to $370 \mathrm{~K}$ in the cryostat under $10^{-4} \mathrm{~Pa}$ pressure slowly by putting it between quartz plate with Nujol (crystal melted around $380 \mathrm{~K}$ under atmospheric pressure in single-crystal measurement, therefore $T=370 \mathrm{~K}$ was chosen for the experiment). The resulting emission spectra show gradual decrease of emission intensity from $10 \mathrm{~K}$ up to $300 \mathrm{~K}$ which can be attributed to the thermal activation of non-radiative relaxation pathways (Fig. 2a). Interestingly, emission intensity starts to increase after heating sample to $325 \mathrm{~K}$ which keep increasing until $370 \mathrm{~K}$ (Fig. 2a). On the other hand, the reverse cooling of the sample increases the emission intensity almost by five times at $10 \mathrm{~K}$ compared with pristine sample. Such behaviour can be explained by the release of the coordinated $\mathrm{MeOH}$ (Fig. S2 and S3, ESI $\dagger$ ) and structural changes associated to this process which suppress nonradiative relaxation pathways and resulting in the more efficient energy transfer between TTA to $\mathrm{Nd}^{3+}$ ions. ${ }^{23 c}$ The reason can be supported by careful analysis of the excitation spectra (Fig. 2b). The peak intensity of the excitation spectra corresponding to transition from ${ }^{0} \mathrm{~S}_{\mathrm{X}}$ (singlet ground state) to ${ }^{1} \mathrm{~S}_{\mathrm{X}}$ (first singlet excited state) and to ${ }^{3} \mathrm{~T}_{\mathrm{X}}$ (triplet excited state) centred around $360 \mathrm{~nm}$ and $392 \mathrm{~nm}$, respectively, changes with respect to temperature. For thermally stimulated sample triplet excited state gets populated more efficiently and transfers energy effectively to the neighbouring lanthanide ion due to better energy match. Moreover, we measured the single crystal structure of $\mathbf{A}$ at higher temperature of $340 \mathrm{~K}$ which indicated that $\mathrm{C}-\mathrm{N}-\mathrm{N}$ bond angles of Azo-py ring changes along with increase in the various bond distances (Fig. 1d and Table S1, ESI $\dagger$ ). Upon looking at the temperature dependence of UV-VISNIR absorption and NIR emission spectra, we precisely studied the temperature dependent changes in the emission peak appearing at $895 \mathrm{~nm}$ in the range $10-300 \mathrm{~K}$ for $392 \mathrm{~nm}$ excitation light as well as $360 \mathrm{~nm}$ light (Fig. 2c, S10-S12 ESI $\dagger$ ). The intensity ratio $\left[\left(I\left({ }^{4} \mathrm{~F}_{3 / 2(2)} \rightarrow{ }^{4} \mathrm{I}_{9 / 2}\right) / I\left({ }^{4} \mathrm{~F}_{3 / 2(1)} \rightarrow{ }^{4} \mathrm{I}_{9 / 2}\right)\right]=\Delta(T)\right)$ of these two peaks also known as thermometric parameter are plotted against temperature for 392 and $360 \mathrm{~nm}$ excitation light (Fig. 2d). The thermometric parameter strongly varies in 25-250 $\mathrm{K}$ for $392 \mathrm{~nm}$ and $10-300 \mathrm{~K}$ for $360 \mathrm{~nm}$ excitation wavelengths. For single centre ratiometric luminescent thermometers resulting data can be fitted by using Boltzmann population method (eqn (1), where $\Delta_{0}$ is the pre-exponential factor, $\Delta E_{0}$ is the energy difference between two emissive levels at reference temperature, $C$ is offset factor, $k_{\mathrm{B}}$ Boltzmann constant and $T$ is absolute temperature; $\Delta_{0}(392)=2.08(7), \Delta_{0}(360)=1.67(7)$, $\Delta E_{0} / k_{\mathrm{B}}(392)=-11.70(6), \Delta E_{0} / k_{\mathrm{B}}(360)=443.88(5), C(392)=0$, 

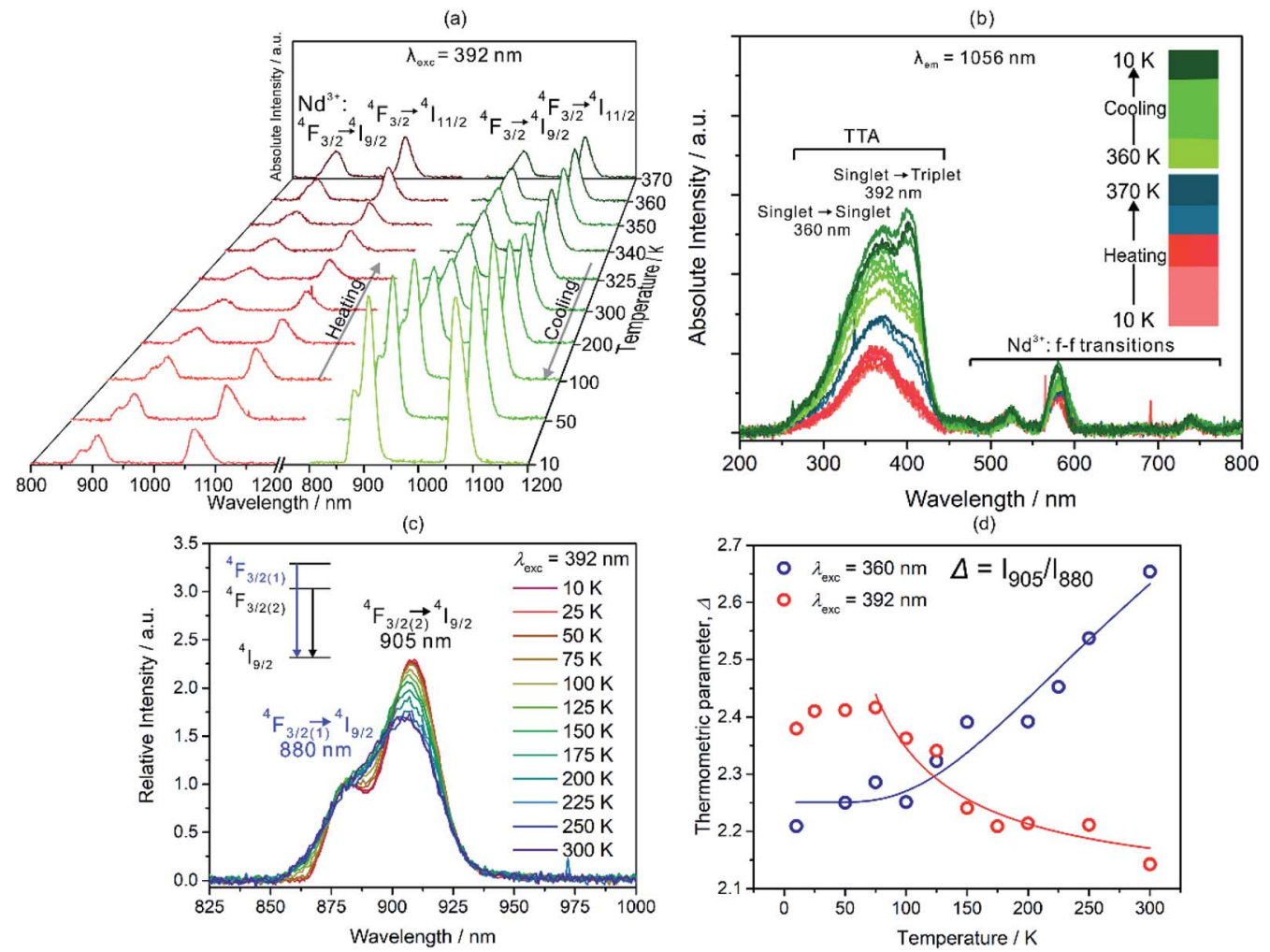

Fig. 2 Solid state temperature dependent NIR emission spectra of A measured in $10 \rightarrow 370 \rightarrow 10 \mathrm{~K}$ temperature cycles for excitation wavelength, $\lambda_{\text {exc }}$ of $392 \mathrm{~nm}$ (a) and the corresponding excitation spectra of A collected at relevant emission wavelength, $\lambda_{\text {em }}$, of $1056 \mathrm{~nm}$ (b); the emission profile at $895 \mathrm{~nm}$ measured at various temperature for $\lambda_{\text {exc }}=392 \mathrm{~nm}$ (c). (d) Presents the temperature dependence of the thermometric parameter, $\Delta$, for $\lambda_{\text {exc }}=392$ and $360 \mathrm{~nm}$ together with the calibration curve (solid line) obtained from the best fit of the classical Mott-Seitz model involving two non-radiative recombination channels.

$C(360)=2.25(0), R^{2}=0.91(5)(392)$ and $0.94(7)(360)$ for $\lambda_{\text {exc }}=$ 392 and $360 \mathrm{~nm}$ respectively) which describes the thermal depopulation of two thermally coupled energy levels. ${ }^{\mathbf{1 1}}$

$$
\Delta(T)=I_{905} / I_{880}=\Delta_{0} \exp \left(-\Delta E_{0} / k_{\mathrm{B}} T\right)+C
$$

The thermometric performance decreases with increasing temperature for $\lambda_{\text {exc }}=392 \mathrm{~nm}$, however it increases for $\lambda_{\text {exc }}=$ $360 \mathrm{~nm}$ which could be assigned to the difference in the population of thermally coupled emissive Stark levels ${ }^{4} \mathrm{~F}_{3 / 2(1)}$ and ${ }^{4} \mathrm{~F}_{3 / 2(2)}$ (Fig. 2d). ${ }^{23}$ The excitation by $392 \mathrm{~nm}$ populates triplet excited state of TTA more than the $360 \mathrm{~nm}$ light irradiation due to better energy matching therefore energy transfer in the former case is more efficient to the ${ }^{4} F_{3 / 2(1)}$ Stark level which results into two opposing thermometric sensing ability (Fig. S12d and e, ESI†).

The sensitivity $\left(S_{\mathrm{r}}\right)$ and uncertainty $(\delta T)$ for these two excitation wavelengths are computed using eqn (2) and (3) which indicated the best working temperature of 75-300 K $\left(0.039<S_{\mathrm{r}}<\right.$ 0.054 and $0.075<\delta T<1.993)$ and $10-300 \mathrm{~K}\left(0.02094<S_{\mathrm{r}}<\right.$ 0.02098 and $0.017<\delta T<1.653$ ) for 392 and $360 \mathrm{~nm}$ excitation wavelength, respectively (Fig. S12d, e, and S13, ESI $\dagger$ ). In addition, we performed thermal heating-cooling cycle in the temperature range of 50-200 $\mathrm{K}$ which shows good repeatability (Fig. S15 and S16, ESI $\dagger$ ).

$$
\begin{gathered}
S_{\mathrm{r}}=\frac{1}{\Delta}\left(\frac{\partial \Delta}{\partial T}\right) \times 100 \\
\delta T=\left(\frac{\delta \Delta}{\Delta}\right) / S_{\mathrm{r}}
\end{gathered}
$$

The direct-current (dc) magnetic properties for $\mathbf{A}$ are indicated in Fig. S17, (ESI $\dagger$ ). The $\chi_{\mathrm{M}} T$ value for $\mathbf{A}$ at $300 \mathrm{~K}$ reaches $1.34 \mathrm{~cm}^{3} \mathrm{~mol}^{-1} \mathrm{~K}$ which is slightly lower than the estimated value of $1.64 \mathrm{~cm}^{3} \mathrm{~mol}^{-1} \mathrm{~K}$ for $\mathrm{Nd}^{3+}$ ions of the ${ }^{4} \mathrm{I}_{9 / 2}$ ground multiplet. The decrease in the magnetization upon cooling can be explained by thermal depopulation of the $m_{\mathrm{J}}$ levels of ground electronic state. The saturation magnetization observed at $1.8 \mathrm{~K}$ in $H_{\mathrm{dc}}=50 \mathrm{kOe}$ equals $1.17 \mu_{\mathrm{B}}$ which is very close to the $1.27 \mu_{\mathrm{B}}$ of expected value for $m_{\mathrm{J}}= \pm 7 / 2$ ground state with Ising anisotropy of $g_{\mathrm{z}}=5.1 .^{22}$ The alternate-current (ac) magnetic studies (Fig. 3, S18 and S19, Table S5, ESI $\dagger$ ) in the optimum dc field of 1000 Oe shows that A exhibits the single molecular magnet behaviour with energy barrier of $\Delta E / k_{\mathrm{B}}=19.7(7) \mathrm{K}$, attempt time of relaxation, $\tau_{0}=3.7(8) \times 10^{-7} \mathrm{~s}$ and the $\tau_{\mathrm{QTM}}{ }^{-1}$ $=1300 \mathrm{~s}^{-1}$ after fitting with Arrhenius law indicated by eqn (4).

$$
\tau^{-1}=\tau_{\mathrm{QTM}}{ }^{-1}+\tau_{0}{ }^{-1} \exp \left(-\Delta E / k_{\mathrm{B}} T\right)
$$


(a)

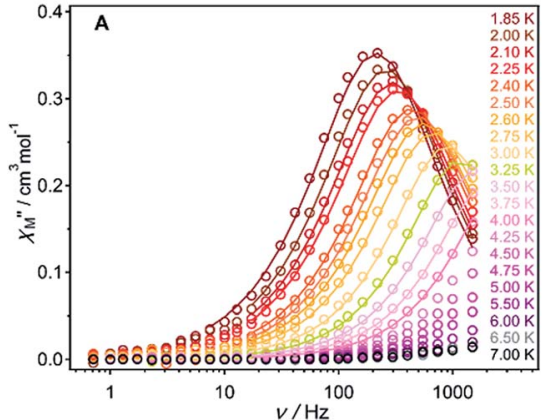

(b)

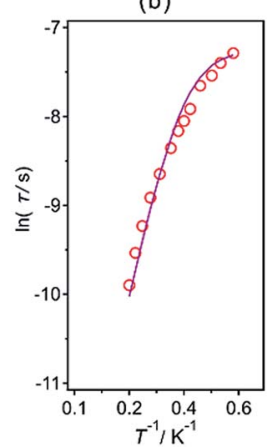

Fig. 3 Ac magnetic properties of $\mathrm{A}\left(H_{\mathrm{dc}}=1000 \mathrm{Oe}\right.$ and $\left.H_{\mathrm{ac}}=3 \mathrm{Oe}\right)$ : frequency $(\nu)$ dependences out-of-plane, $\chi_{M}^{\prime \prime}$ (a) components of the magnetic susceptibility for the indicated temperatures in $1.85-7.0 \mathrm{~K}$ range and the temperature dependence of relaxation times $(\tau)$ presented as $\ln (\tau)$ versus $T^{-1}$ plots (b). Solid lines in (a) and (b) were fitted using the generalized Debye model (Table S8, ESI $\dagger$ ) and eqn (4), respectively.

The magnetic-field induced single relaxation process can be assigned to the thermal relaxation behaviour with small contribution of quantum tunnelling of magnetization (QTM) at lower temperature. Thus, A acts as single molecule magnet generally rare among TTA based $\mathrm{Nd}^{\mathrm{III}}$ complex (Fig. 3 and Table $\mathrm{S} 6, \mathrm{ESI} \dagger)$. We also measured the ac magnetic properties for the heated sample (in the similar condition like sample used for the luminescence measurement) under applied magnetic field of 1000 Oe. The heated sample of $\mathbf{A}$ shows slightly improved energy barrier of $\Delta E / k_{\mathrm{B}}=27.3 \mathrm{~K}$, attempt time of relaxation $\tau_{0}=$ $8.5(0) \times 10^{-8}$ and the $\tau_{\mathrm{QTM}}{ }^{-1}=1201 \mathrm{~s}^{-1}$ (Fig. S20, ESI $\dagger$ ). The slight enhancement of energy barrier could be attributed to the fact that magnetic anisotropy of the $\mathrm{Nd}^{3+}$ ion improved due to release of two co-ordinating methanol (Fig. S2, ESI†).

\section{Conclusions}

In conclusion, we synthesized dinuclear coordination network $\left[\mathrm{Nd}^{\mathrm{III}}(\mathrm{TTA})_{3}(\mathrm{MeOH})_{2}\right] \cdot 0.5 \mathrm{Azo}-\mathrm{py}(\mathbf{A})$ in which two asymmetric units are linked by an organic linker with hydrogen bonds. The crystalline compound reveals temperature dependent NIR emission as well as SMM properties. Upon heating the luminescence intensity increases by almost five times which is assigned to the thermally stimulated emission due to suppression of non-radiative relaxation pathways, hence, efficient energy transfers from TTA to $\mathrm{Nd}^{3+}$ ions. Additionally, NIR emission intensity can be modulated by temperature, which helped us to design a ratiometric thermometer in the temperature range $10-300 \mathrm{~K}$. In the future, we will focus on the exploration of correlation between magnetic properties and ratiometric emission behaviour and the observation of the external stimuli effect on such phenomenon.

\section{Conflicts of interest}

There are no conflicts to declare.

\section{Acknowledgements}

The present research was partially supported by the Grant-inAid for Specially Promoted Research (Grant number 15H05697), Grants-in-Aid for Scientific Research on Innovative Areas Soft Crystals (area no. 2903, 17H06367) and APSA from MEXT. The Global Science course from MEXT, the Cryogenic Research Center in The University of Tokyo, and the Center for Nano Lithography \& Analysis in The University of Tokyo supported by MEXT, and Quantum Leap Flagship Program (QLEAP) by MEXT are acknowledged.

\section{Notes and references}

1 (a) K. Kato, Y. Moritomo, M. Takata, M. Sakata, M. Umekawa, N. Hamada, S. Ohkoshi, H. Tokoro and K. Hashimoto, Phys. Rev. Lett., 2003, 91, 255502; (b) T. Mahfoud, G. Molnar, S. Bonhommeau, S. Cobo, L. Salmon, P. Demont, H. Tokoro, S. Ohkoshi, K. Boukheddaden and A. Bousseksou, J. Am. Chem. Soc., 2009, 131, 15049; (c) S. Ohkoshi, K. Imoto, Y. Tsunobuchi, S. Takano and H. Tokoro, Nat. Chem., 2011, 3, 564; (d) S. Ohkoshi and H. Tokoro, Acc. Chem. Res., 2012, 45, 1749; (e) D. M. Pajerowski, M. J. Andrus, J. E. Gardner, E. S. Knowles, M. W. Meisel and D. R. Talham, J. Am. Chem. Soc., 2010, 132, 4058; (f) O. Sato, T. Iyoda, A. Fujishima and K. Hashimoto, Science, 1996, 272, 704; $(g)$ R. González, A. Acosta, R. Chiozzone, C. Kremer, D. Armentano, G. De Munno, M. Julve, F. Lloret and J. Faus, Inorg. Chem., 2012, 51, 5737; (h) J. Werner, Z. Tomkowicz, M. Rams, S. G. Ebbinghaus, T. Neumann and C. Näther, Dalton Trans., 2015, 44, 14149; (i) P. F. Yan, P. H. Lin, F. Habib, T. Aharen, M. Murugesu, Z. P. Deng, G. M. Li and W. B. Sun, Inorg. Chem., 2011, 50, 7059; (j) M. Verdaguer, A. Bleuzen, V. Marvaud, J. Vaissermann, M. Seuleiman, C. Desplanches, A. Scuiller, C. Train, R. Garde, G. Gelly, C. Lomenech, I. Rosenman, P. Veillet, C. Cartier and F. Villain, Coord. Chem. Rev., 1999, 192, 1023; (k) J. S. Miller, Chem. Soc. Rev., 2011, 40, 3266; (l) K. R. Dunbar and R. A. Heintz, Prog. Inorg. Chem., 1996, 45, 283; $(m)$ B. Nowicka, O. Stefańczyk, D. Pinkowicz, S. Chorazy, R. Podgajny and B. Sieklucka, Coord. Chem. Rev., 2012, 256, 1946; (n) F. Pointillart, O. Cador, B. Le Guennic and L. Ouahab, Coord. Chem. Rev., 2017, 346, 150.

2 (a) J.-C. G. Bünzli and C. Piguet, Chem. Soc. Rev., 2005, 34, 1048; (b) K. Binnemans, Chem. Rev., 2009, 109, 4283; (c) J. Rocha, L. D. Carlos, F. A. Almeida Paz and D. Ananias, Chem. Soc. Rev., 2011, 40, 926; (d) Y. Yamada, D. Koori, K. Mori and Y. Oshikawa, J. Coord. Chem., 2016, 69, 3735.

3 (a) S. Ohkoshi, H. Tokoro, T. Hozumi, Y. Zhang, K. Hashimoto, C. Mathoniere, I. Bord, G. Rombaut, M. Verelst, C. C. D. Moulin and F. Villain, J. Am. Chem. Soc., 2006, 128, 270; (b) S. Ohkoshi, Y. Yamada, T. Matsuda, Y. Tsunobuchi and H. Tokoro, Chem. Mater., 2008, 20, 3048; (c) S. Ohkoshi, S. Takano, K. Imoto, M. Yoshikiyo, A. Namai and H. Tokoro, Nat. Photonics, 2014, 8, 65. 
4 (a) E. Chelebaeva, J. Larionova, Y. Guari, R. A. S. Ferreira, L. D. Carlos, F. A. Almeida Paz, A. Trifonov and C. Guerin, Inorg. Chem., 2009, 48, 5983; (b) S. Chorazy, M. Arczynski, K. Nakabayashi, B. Sieklucka and S. Ohkoshi, Inorg. Chem., 2015, 54, 4724; (c) J. Long, R. Vallat, R. A. S. Ferreira, L. D. Carlos, F. A. Almeida Paz, Y. Guari and J. Larionova, Chem. Commun., 2012, 48, 9974; (d) F. Pointillart, B. Le Guennic, S. Golhen, O. Cador and L. Ouahab, Chem. Commun., 2013, 49, 11632.

5 (a) S. Ohkoshi, K. Arai, Y. Sato and K. Hashimoto, Nat. Mater., 2004, 3, 857; (b) K. Imoto, D. Takahashi, Y. Tsunobuchj, W. Kosaka, M. Arai, H. Tokoro and S. Ohkoshi, Eur. J. Inorg. Chem., 2010, 26, 4079; (c) N. Yanai, W. Kaneko, K. Yoneda, M. Ohba and S. Kitagawa, J. Am. Chem. Soc., 2007, 129, 3496.

6 (a) N. B. D. Lima, A. I. S. Silva, P. C. Gerson, S. M. C. Gonçalves and A. M. Simas, PLoS One, 2015, 10, e0143998; (b) B. Rajamouli and V. Sivakumar, ChemistrySelect, 2017, 14, 4138.

7 (a) P. Chen, Q. Li, S. Grindy and N. Holten-Andersen, J. Am. Chem. Soc., 2015, 137, 11590; (b) L. V. Meyer, F. Schönfeld and K. Müller-Buschbaum, Chem. Commun., 2014, 50, 8093; (c) S. Chorazy, K. Kumar, K. Nakabayashi, B. Sieklucka and S. Ohkoshi, Inorg. Chem., 2017, 56, 5239; (d) K. S. Kisel, G. Linti, G. L. Starova, V. V. Sizov, A. S. Melnikov, A. P. Pushkarev, M. N. Bochkarev, E. V. Grachova and S. P. Tunik, Eur. J. Inorg. Chem., 2015, 2015, 1734; (e) V. V. Khistiaeva, A. S. Melnikov, S. O. Slavova, V. V. Sizov, G. L. Starova, I. O. Koshevoy and E. V. Grachova, Inorg. Chem. Front., 2018, 5, 3015.

8 (a) N. M. Shavaleev, L. P. Moorcraft, S. J. A. Pope, Z. R. Bell, S. Faulkner and M. D. Ward, Chem. Commun., 2003, 10, 1134; (b) G. M. Davies, S. J. A. Pope, H. Adams, S. Faulkner and M. D. Ward, Inorg. Chem., 2005, 44, 4656; (c) K. A. White, D. A. Chengelis, K. A. Gogick, J. Stehman, N. L. Rosi and S. Petoud, J. Am. Chem. Soc., 2009, 131, 18069; (d) S. Chorazy, M. Rams, J. Wang, B. Sieklucka and S. Ohkoshi, Dalton Trans., 2017, 46, 13668.

9 (a) J. Kido and Y. Okamoto, Chem. Rev., 2002, 102, 2357; (b) J. L. Sessler and R. A. Miller, Biochem. Pharmacol., 2000, 59, 733; (c) J. D. Rinehart and J. R. Long, Dalton Trans., 2012, 41, 13572.

10 (a) I. V. Taydakov, A. A. Akkuzina, R. I. Avetisov, A. V. Khomyakov, R. R. Saifutyarov and I. Ch. Avetissov, J. Lumin., 2016, 177, 31; (b) I. Savchenko, A. Berezhnytska, E. Trunova, N. Rusakova and G. Grozduyk, Mol. Cryst. Liq. Cryst., 2016, 640, 134.

11 (a) K. Kumar, S. Chorazy, K. Nakabayashi, H. Sato, B. Siecklucka and S. Ohkoshi, J. Mater. Chem. C, 2018, 6, 8372; (b) H. Kusama, O. J. Sovers and T. Yoshioka, Jpn. J. Appl. Phys., 1976, 15, 2349; (c) J.-C. G. Bünzli and V. K. Pecharsky, Handbook on the Physics and Chemistry of Rare Earths, Elsevier, 2016, ch. 281, vol. 49.

12 M. C. Burla, R. Caliandro, M. Camalli, B. Carrozzini, G. L. Cascarano, C. Giacovazzo, M. Mallamo, A. Mazzone, G. Polidori and R. Spagna, J. Appl. Crystallogr., 2012, 45, 357.
13 G. M. Sheldrick, Acta Crystallogr., Sect. A: Found. Crystallogr., 2008, 64, 112.

14 CrystalStructure Version 4.2, Rigaku Corporation, Tokyo, Japan, 2017.

15 G. M. Sheldrick, SHELXL 2018, University of Göttingen, Germany, 2018.

16 C. F. Macrae, I. J. Bruno, J. A. Chisholm, P. R. Edgington, P. McCabe, E. Pidcock, L. Rodriguez-Monge, R. Taylor, J. van der Streek and P. A. Wood, J. Appl. Crystallogr., 2008, 41, 466.

17 M. J. Frisch, G. W. Trucks, H. B. Schlegel, G. E. Scuseria, M. A. Robb, J. R. Cheeseman, G. Scalmani, V. Barone, B. Mennucci, G. A. Petersson, H. Nakatsuji, M. Caricato, X. Li, H. P. Hratchian, A. F. Izmaylov, J. Bloino, G. Zheng, J. L. Sonnenberg, M. Hada, M. Ehara, K. Toyota, R. Fukuda, J. Hasegawa, M. Ishida, T. Nakajima, Y. Honda, O. Kitao, H. Nakai, T. Vreven, J. A. Montgomery Jr, J. E. Peralta, F. Ogliaro, M. Bearpark, J. J. Heyd, E. Brothers, K. N. Kudin, V. N. Staroverov, T. Keith, R. Kobayashi, J. Normand, K. Raghavachari, A. Rendell, J. C. Burant, S. S. Iyengar, J. Tomasi, M. Cossi, N. Rega, J. M. Millam, M. Klene, J. E. Knox, J. B. Cross, V. Bakken, C. Adamo, J. Jaramillo, R. Gomperts, R. E. Stratmann, O. Yazyev, A. J. Austin, R. Cammi, C. Pomelli, J. W. Ochterski, R. L. Martin, K. Morokuma, V. G. Zakrzewski, G. A. Voth, P. Salvador, J. J. Dannenberg, S. Dapprich, A. D. Daniels, Ö. Farkas, J. B. Foresman, J. V. Ortiz, J. Cioslowski and D. J. Fox, Gaussian 09, Revision C.01, Gaussian, Inc., Wallingford CT, 2010.

18 A. D. Becke, J. Chem. Phys., 1993, 98, 5648.

19 M. Llunell, D. Casanova, J. Cirera, J. Bofill, P. Alemany, S. Alvarez, M. Pinsky and D. Avnir, SHAPE v. 2.1. Program for the Calculation of Continuous Shape Measures of Polygonal and Polyhedral Molecular Fragments, University of Barcelona, Barcelona, Spain, 2013.

20 C. Seward and S. Wang, Can. J. Chem., 2001, 79, 1187.

21 (a) J. G. White, Inorg. Chim. Acta, 1976, 16, 159; (b) V. Vallet, A. Fischer, Z. Szabo and I. Grenthe, Dalton Trans., 2010, 39, 7666; (c) P. S. Barber and A. de Bettencourt-Dias, Acta Crystallogr., Sect. E: Struct. Rep. Online, 2011, 67, m1188; (d) G. Zucchi, P. Thuery, and M. Ephritikhine, CCDC 909451: Experimental Crystal Structure Determination, 2013, DOI: $10.5517 /$ cczjc 4 z.

22 S. Chorazy, T. Charytanowicz, J. Wang, S. Ohkoshi and B. Sieklucka, Dalton Trans., 2018, 47, 7870.

23 (a) O. A. Savchuk, J. J. Carvajal, L. G. De la Cruz, P. HaroGonzalez, M. Aguilo and F. Diaz, J. Mater. Chem. C, 2016, 4, 7397; (b) U. Rocha, C. Jacinto, W. F. Silva, I. Guedes, A. Benayas, L. M. Maestro, M. A. Elias, E. Bovero, F. C. J. M. van Veggel, J. G. Solé and D. Jaque, ACS Nano, 2013, 7, 1188; (c) A. M. Kaczmarek, D. Esquivel, J. Ouwehand, P. V. D. Voort, F. J. Romero-Salguero and R. V. Deun, Dalton Trans., 2017, 46, 7878. 